\title{
First Line Treatment for Advanced Gastroesophageal Cancer: Capecitabine Plus Oxaliplatin (CAPOX) versus Epirubicin, Oxaliplatin Plus Capecitabine (EOX)
}

\author{
Pani CK', Dubashi B ${ }^{1}$, Cyriac SL ${ }^{1}$, Dhanraj KM1, \\ Verma SK ${ }^{2}$, Sistla SC $^{3}$ and Kayal $\mathbf{S}^{1 *}$ \\ ${ }^{1}$ Department of Medical Oncology, J awaharlal Institute \\ of Postgraduate Medical Education and Research \\ (J IPMER), India \\ ${ }^{2}$ Department of Pathology, J awaharlal Institute \\ of Postgraduate Medical Education and Research \\ (J IPMER), India \\ ${ }^{3}$ Department of Surgery, J awaharlal Institute of \\ Postgraduate Medical Education and Research \\ (J IPMER), India \\ *Corresponding author: Kayal S, Department of \\ Medical Oncology, Regional Cancer Centre, J IPMER, \\ Dhanvantari Nagar, Puducherry-605006, India
}

Received: J anuary 27, 2017; Accepted: February 27, 2017; Published: March 01, 2017

\begin{abstract}
Chemotherapy is the mainstay of treatment for advanced gastroesophageal cancer (AGC). There is no consensus whether doublet or triplet chemotherapy is better. Hence our study aimed to compare CAPOX (capecitabine and oxaliplatin) with EOX (epirubicin, oxaliplatin plus capecitabine) as first line treatment for AGC. From December 2012 to July 2014, total of 69 patients were randomly assigned; 35 to EOX arm (epirubicin $50 \mathrm{mg} / \mathrm{m}^{2}$ on day1, capecitabine $625 \mathrm{mg} / \mathrm{m}^{2}$ twice daily for 21 day and oxaliplatin $130 \mathrm{mg} / \mathrm{m}^{2}$ on day1 three weekly for 8 cycle) and 34 to CAPOX arm (capecitabine $1000 \mathrm{mg} / \mathrm{m}^{2}$ twice daily for 14 days and oxaliplatin $130 \mathrm{mg} / \mathrm{m}^{2}$ on day 1 in a three weekly cycle for 8 cycle). Median age at diagnosis was 55 years. The median number of chemotherapy cycle delivered was $7.45 \%$ completed planned treatment. $63.8 \%$ patient needed dose modification and $33.3 \%$ had treatment discontinuation due to grade $3 / 4$ toxicity. Incidence of grade $3 / 4$ neutropenia was significantly more in EOX where as diarrhoea and vomiting were more in CAPOX group. The ORR (overall response rate) was $63 \%$ in the entire cohort and $54.5 \%$ and $71.4 \%$ in the CAPOX and EOX group respectively. Median follow up was 15.2 month. Median OS (overall survival) was 8.1 and 10.3 months in the CAPOX and EOX groups respectively; $p=0.298$, however there was a trend favouring PFS (progression free survival) in the EOX group (5.5 vs. 8.3 months in CAPOX and $E O X$ respectively; $p=0.06$ ). No significant difference was observed between the two regimens with respect to ORR, PFS and OS. Doublet chemotherapy regimen (CAPOX) has similar efficacy as a triplet regimen (EOX), however, with higher incidence of gastrointestinal toxicity.
\end{abstract}

Keywords: Advanced gastric cancer; Palliative chemotherapy; Epirubicin; Oxaliplatin; Capecitabine

\section{Abbreviations}

AGC: Advanced Gastroesophageal Cancer; ALT: Alanine Transaminase; ALP: Alkaline Phosphatise; AST: Aspartate Transaminase; CAPOX: Capecitabine and Oxaliplatin; CR: Complete Response; EOX: Epirubicin, Oxaliplatin Plus Capecitabine; ECOG: Eastern Co-Operative Group; GEJ: Gastro Esophageal Junction; HR: Hazard Ratio; NCI-CTCAE: National Cancer Institute Common Terminology Criteria for Adverse Events; ORR: Overall Response Rate; OS: Overall Survival; PD: Progressive Disease; PFS: Progression Free Survival; PR: Partial Response; RECIST: Response Evaluation Criteria in Solid Tumors; SD: Stable Disease; TTP: Time To Progression; ULN: Upper Limit of Normal

\section{Introduction}

Gastric cancer is the fifth most common cancer and third most common cause of death worldwide. Despite recent advances in the diagnosis and treatment of gastric cancer, many patients present with advanced disease and have poor survival [1]. According to data from the National Cancer Institute Surveillance, Epidemiology and End Results (SEER) Program, the five-year survival for patients with gastric cancer improved only modestly over the last 50 years, from 12 percent in the years 1950 to 1954,22 percent during the period 1996 to 2003 [2]. The median survival for advanced gastric cancer is about four months without treatment, and this extends up to one year with current treatment modalities. Chemotherapy is the mainstay of treatment for advanced gastroesophageal cancer (AGC). Initial trials used single agent drugs versus best supportive care. Subsequent studies showed that combination chemotherapy result in superior outcomes compared to monotherapy [3]. Triple drug regimen is better than double in the form of increased overall response rate (ORR) and time to progression (TTP) but is associated with increased myelosuppression and infectious complications [4]. The recent REAL-2 trial has proven that capecitabine is equivalent to 5 -FU and oxaliplatin is equivalent to cisplatin with comparable or even more response rate and survival [5]. Combination therapies using cisplatin and fluoropyrimidines with or without epirubicin or docetaxel have been widely used as first-line treatments for AGC. There is no strong data whether doublet or triplet chemotherapy is better, though ORR and TTP favors triplet regimen, there is increased toxicity. We conducted a pilot study at our centre of capecitabine and oxaliplatin (CAPOX) in locally advanced and metastatic gastroesophageal cancer (unpublished data) that showed an ORR of $47.3 \%$, and median survival of 8 months, which are at par with
Austin J Cancer Clin Res - Volume 4 Issue 1 - 2017 ISSN : 2381-909X | www.austinpublishing group.com Kayal et al. (C) All rights are reserved
Citation: Pani CK, Dubashi B, Cyriac SL, Dhanraj KM, Verma SK, Sistla SC, et al. First Line Treatment for Advanced Gastroesophageal Cancer: Capecitabine Plus Oxaliplatin (CAPOX) versus Epirubicin, Oxaliplatin Plus Capecitabine (EOX). Austin J Cancer Clin Res. 2017; 4(1): 1073. 
Table 1: Baseline patient characteristics.

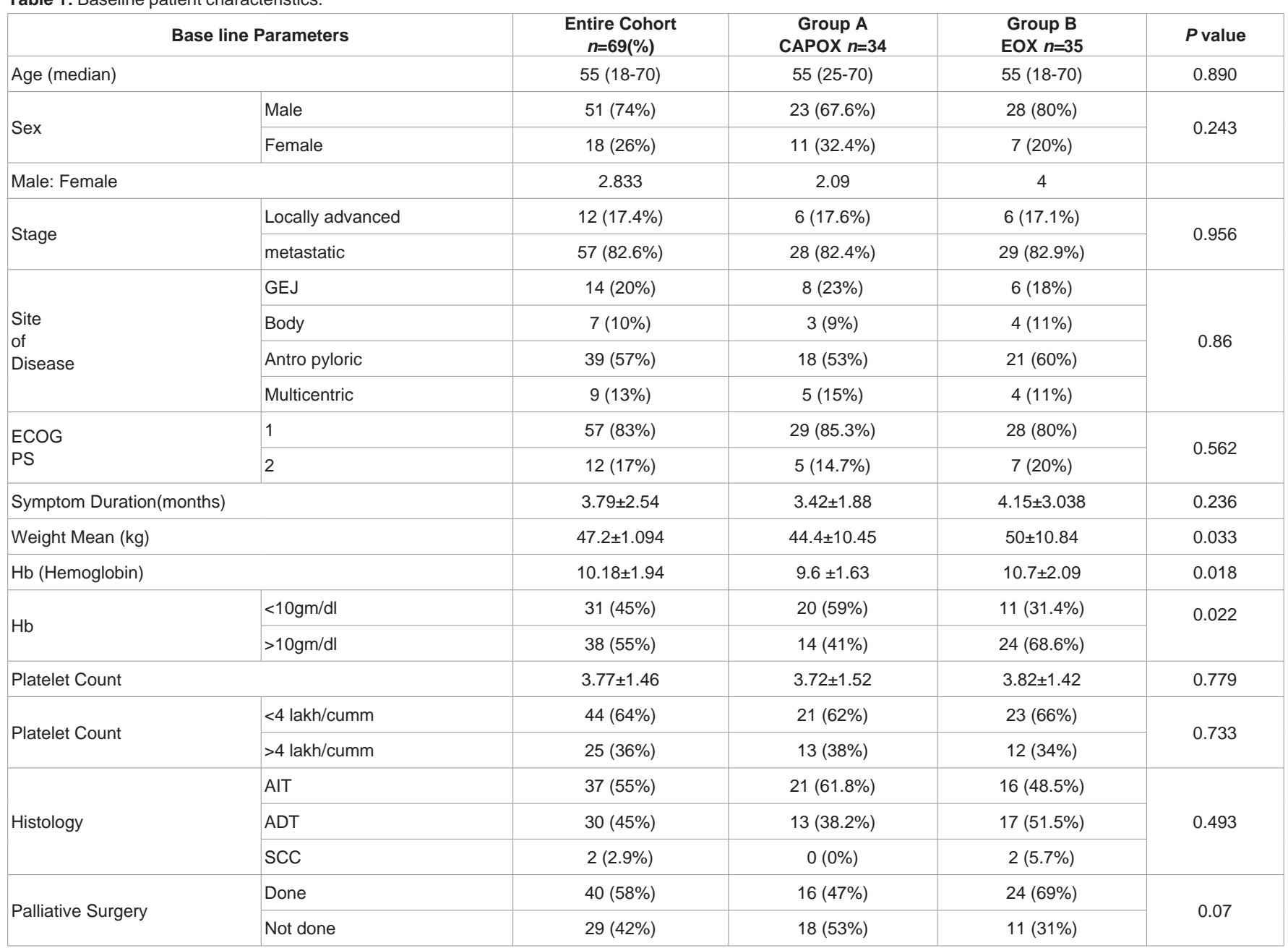

ADT: Adenocarcinoma Diffuse Type; AIT: Adenocarcinoma Intestinal Type; ECOG PS: Eastern Co Operative Group Performance Status; GEJ: Gastroesophageal Junction; SCC: Squamous Cell Carcinoma

current literature. With this encouraging data we planned to conduct a randomized clinical study comparing CAPOX with epirubicin, capecitabine and oxaliplatin (EOX) in AGC.

\section{Methods}

It was a single centre randomized prospective clinical study conducted in the department of Medical Oncology, Regional Cancer Centre, JIPMER, Puducherry. Patients were randomized by computer generated simple randomization method. The main inclusion criteria were histologically proven adenocarcinoma or squamous cell carcinoma of gastric or gastroesophageal region, locally advanced and metastatic disease, age 18-70 years, Eastern cooperative group (ECOG) performance status less than equal to 2 after initial stabilization, able to take oral medication, Chemotherapy naïve patients and a valid informed consent. The exclusion criteria were prior radiotherapy/ chemotherapy, significant organ dysfunction (Ejection fraction $<50 \%$, serum Creatinine $>2 \mathrm{mg} / \mathrm{dl}$, alanine transaminase (ALT) and aspartate transaminase (AST) $\geq 3$ times upper limit of nominal (ULN), alkaline phosphatase (ALP) $\geq 5$ times ULN, serum bilirubin $>3 \mathrm{mg} / \mathrm{dl}$ ) and concomitant malignancy. The study was started after approval by the Institute Ethics Committee.

\section{Patient characteristics}

A total of 69 patients were enrolled during the study period from February 2013 to July 2014 and data was analyzed in December 2014. Patients were randomly assigned to CAPOX arm (group A, n=34) and to EOX arm (group B, $\mathrm{n}=35$ ). Multiple sites of metastasis and ascites were seen in one-third of cases. Palliative surgical intervention in the form of gastric bypass surgery, feeding jejunostomy was done in $58 \%$ of our patients. The baseline patient and disease characteristics (Table 1) were similar in both groups except mean weight at presentation $(44.4 \pm 10.45 v s .50 \pm 10.84, \mathrm{p}=0.033)$ and mean hemoglobin at presentation $(9.6 \pm 1.63$ vs. $10.7 \pm 2.09, \mathrm{p}=0.018)$, which were significantly high in the EOX arm.

\section{Treatment}

Eligible patients were allotted to one of the 2 groups after randomization. Group A i.e. CAPOX chemotherapy schedule included Oxaliplatin $130 \mathrm{mg} / \mathrm{m}^{2}$ IV infusion over two hours on day 1 and Capecitabine $1000 \mathrm{mg} / \mathrm{m}^{2}$ orally twice daily on days 1 to 14 in a 21 day treatment cycle for 8 cycle [6]. Group B i.e. EOX chemotherapy schedule included Epirubicin $50 \mathrm{mg} / \mathrm{m}^{2}$ iv bolus, Oxaliplatin 130 $\mathrm{mg} / \mathrm{m}^{2} \mathrm{IV}$ infusion over two hours on day 1 and Capecitabine 625 
Table 2: Course of chemotherapy delivery.

\begin{tabular}{|c|c|c|c|c|c|}
\hline \multicolumn{2}{|c|}{ Chemotherapy delivery } & Entire Group $(n=69)$ & $\begin{array}{c}\text { Group A } \\
\text { CAPOX }(n=34)\end{array}$ & $\begin{array}{c}\text { Group B } \\
\text { EOX }(n=35)\end{array}$ & $P$ value \\
\hline \multicolumn{2}{|c|}{ Median no of cycle (range) } & $7(2-8)$ & $6.5(3-8)$ & $8(2-8)$ & 0.241 \\
\hline \multicolumn{2}{|c|}{ No of patients who completed planned treatment } & $31(44.9 \%)$ & $13(41.9 \%)$ & $18(58.1 \%)$ & 0.271 \\
\hline \multicolumn{2}{|c|}{ Treatment discontinuation due to chemotoxicity } & $23(33.3 \%)$ & $15(44 \%)$ & $8(22.9 \%)$ & 0.061 \\
\hline \multicolumn{2}{|c|}{ No of patients with dose modification } & $44(63.8 \%)$ & $24(70.6 \%)$ & $20(57.1 \%)$ & 0.245 \\
\hline \multirow{3}{*}{$\begin{array}{l}\text { Chemotherapy dose } \\
\text { modification }\end{array}$} & capecitabine & $43(62.3 \%)$ & $24(70.6 \%)$ & 19 (54.3\%) & 0.163 \\
\hline & oxaliplatin & $14(20.2 \%)$ & $8(23.5 \%)$ & $6(17.1 \%)$ & 0.510 \\
\hline & epirubicin & $6(8.7 \%)$ & 0 & $6(17.1 \%)$ & \\
\hline
\end{tabular}

Table 3: Adverse events in the chemotherapy regimens.

\begin{tabular}{|c|c|c|c|c|c|}
\hline \multirow{2}{*}{ Adverse event } & \multicolumn{2}{|c|}{ Incidence of any grades of adverse event (per cycle) } & \multicolumn{3}{|c|}{$\begin{array}{l}\text { Rates of grade } 3 / 4 \text { adverse events } \\
\text { (per patient) }\end{array}$} \\
\hline & $\begin{array}{c}\text { Group A } \\
\text { CAPOX }(n=201)\end{array}$ & $\begin{array}{c}\text { Group B } \\
\text { EOX }(n=227)\end{array}$ & $\begin{array}{c}\text { Group A } \\
\text { CAPOX }(n=34)\end{array}$ & $\begin{array}{c}\text { Group B } \\
\text { EOX }(n=35)\end{array}$ & p \\
\hline Anemia & $38(18.9 \%)$ & 17 (7.4\%) & 0 & $2(5.7 \%)$ & 0.493 \\
\hline Neutropenia & $15(7.4 \%)$ & $22(9.7 \%)$ & $1(2.9 \%)$ & $8(22.8 \%)$ & 0.028 \\
\hline Thrombocytopenia & $21(10.4 \%)$ & $18(7.9 \%)$ & $3(8.8 \%)$ & $6(17.1 \%)$ & 0.477 \\
\hline Nausea & $77(38.3 \%)$ & $59(26 \%)$ & $1(2.9 \%)$ & 0 & 0.493 \\
\hline Vomiting & $90(44.7 \%)$ & $58(25.5 \%)$ & $8(23.5 \%)$ & 0 & 0.002 \\
\hline Diarrhea & $63(31.3 \%)$ & $54(23.8 \%)$ & $6(17.6 \%)$ & 0 & 0.011 \\
\hline Mucositis & $12(5.9 \%)$ & $4(1.7 \%)$ & $4(11.7 \%)$ & $1(2.8 \%)$ & 0.198 \\
\hline HFS & $96(47.7 \%)$ & $92(40.5 \%)$ & $3(8.8 \%)$ & $3(8.6 \%)$ & 0.970 \\
\hline Peripheral neuropathy & $55(27.36 \%)$ & $47(20.7 \%)$ & $1(2.9 \%)$ & $1(2.8 \%)$ & 1.000 \\
\hline DVT & $2(1 \%)$ & $5(2.2 \%)$ & 0 & 0 & - \\
\hline
\end{tabular}

HFS: Hand Foot Syndrome; DVT: Deep Vein Thrombosis

$\mathrm{mg} / \mathrm{m}^{2}$ orally twice daily on days 1 to 21 in a 21 day treatment cycle for 8 cycle [5]. Adverse effects were clinically assessed and graded as per NCI common terminology criteria for adverse event (NCICTCAE) version 4.0 [7]. Patients were monitored minimum twice on outpatient basis in each cycle and more frequently if any adverse event occurred. Patients who had reached the primary endpoint i.e. progressed anytime during the study, either on therapy or after completion during follow-up, and with a good PS were considered for second line chemotherapy with Docetaxel $75 \mathrm{mg} / \mathrm{m}^{2} \mathrm{q} 3$ weekly for 6 cycles. For patients with poor performance status on progression best supportive care was given. Fluorouracil, oxaliplatin and irinotecan (FOLFIRI) was given as a third line chemotherapy for eligible patients.

\section{Assessment}

Progression free survival (PFS) was defined as the time from the randomization to radiologically proven progressive disease (PD) or death without prior PD, whichever came first. All images for tumor responses were reviewed by internal radiologist, according to the Response Evaluation Criteria in Solid Tumors (RECIST) version 1.1 [8]. Overall survival (OS) was defined as the interval from randomization to death from any cause or the date of last follow-up.

\section{Statistical consideration}

Descriptive statistics was used for baseline characteristics, disease factors \& treatment details. Secondary outcome variables (response rate, toxicities) were analyzed using Chi-square/ Fisher's exact test. OS and PFS were estimated using the Kaplan -Meier method and differences between groups were examined by Log rank test. Median follow-up time was calculated using the Kaplan-Meier method for potential follow up. Cox regression (univariate and multivariate) method for proportional hazard was used to identify significant predictors of survival outcome. Censoring for survival analysis was done on 31st December 2014. SPSS v 19.0 was used for analysis.

\section{Results}

\section{Treatment delivery}

A total of 428 chemotherapy cycles were administered, CAPOX accounting for 201 cycles and EOX for 227. Median number of cycles was 7 (range, 2-8). Median treatment duration was 171 days. Planned treatment was completed in $45 \%(n=31)$ patients. Treatment discontinuation due to grade $3 / 4$ chemotoxicity was seen in $33.3 \%$ $(n=23)$ patients; $44 \%(n=15)$ and $30 \%(n=8)$ in the CAPOX and EOX group respectively $(\mathrm{p}=0.06)$. Dose modification was required in $63.8 \%$ $(\mathrm{n}=44)$ of patients. Capecitabine and oxaliplatin dose modification were seen in $62 \%(n=43)$ and $20 \%(n=14)$ patients respectively. There were no significant differences between the two groups in relation to number of chemotherapy cycle administered and dose modification (Table 2).

\section{Safety}

A total of 201 chemotherapy cycles were administered in CAPOX group and 227 cycles in EOX group. Incidence of any grade of toxicity (per cycle) between CAPOX and EOX group is summarized in Table 3. Occurence of grade $3 / 4$ toxicities is summarized and 

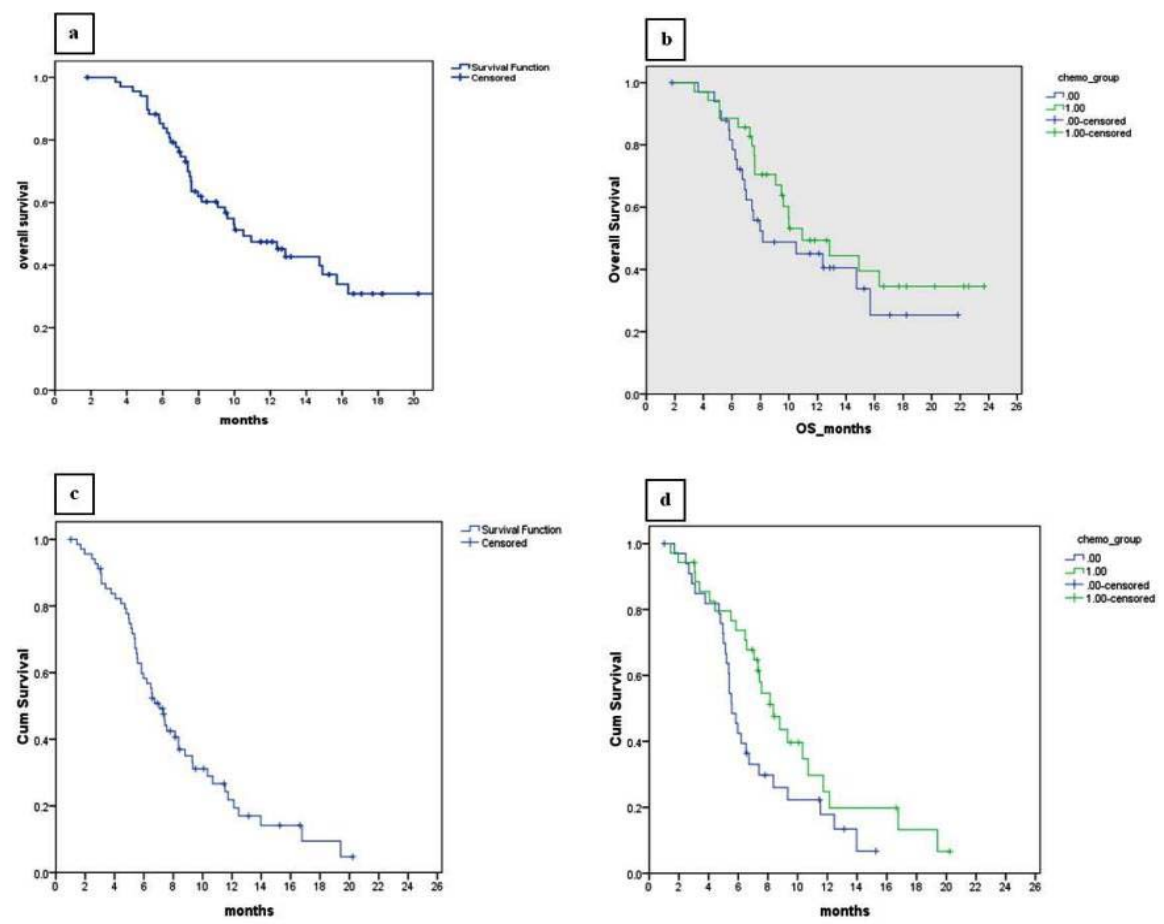

Figure 1: Kaplan-Meier curve for Overall Survival - (A) for entire cohort and (B) for study groups CAPOX (Group 0) and EOX (Group 1); and for Progression-free survival - (C) for entire cohort and (D) for CAPOX (Group-0) and EOX (Group-1).

compared beteween two groups in Table 3 . The incidence of grade $3 / 4$ neutropenia was significantly more in EOX where as diarrhoea and vomiting were more in CAPOX group.

\section{Efficacy}

The ORR [i.e. complete response (CR), partial response (PR), stable disease (SD)] was $62.3 \%$ in the entire cohort and $52.9 \%(\mathrm{n}=18)$ and $71.4 \%(\mathrm{n}=25)$ in the CAPOX group and EOX group respectively, $(\mathrm{p}=0.149)$. The CR, PR and SD rates were $10 \%, 42 \%, 10 \%$ respectively in the entire patient population and response rates were not statistically significant between the two study groups ( $\mathrm{p}=0.444)$.

After a median follow-up of 15.2 months (3.26 - 23.66 month), the median OS was 10.5 months and PFS was 7 months in entire patient cohort while the estimated 1 year OS and PFS were $47.4 \%$ and $21.8 \%$ respectively. There was no significant difference in the median OS (8.1 and 10.9 months in the CAPOX and EOX groups respectively, $\mathrm{p}=0.298$ ), however there was a trend favouring PFS in the EOX group (5.5 vs. 8.3 months in CAPOX and EOX respectively, $\mathrm{p}=0.06$ ). Survival results of the two study groups are shown in Figure 1. At the time of the final analysis, 14 patients of CAPOX group and 16 in EOX group were alive. Second line therapy consisted of docetaxel in 7 patients; metronomic capecitabine therapy in 9 patients, and 4 patients received and tolerated third line FOLFIRI chemotherapy. Out of 14 patients alive in CAPOX group 1 was in CR, 7 in PR and 6 were in progressive disease. Out of 16 patients alive in EOX group, 6 were in PR and 10 in PD.

\section{Prognostic factors for PFS and OS}

Except for site of disease and response to chemotherapy none of the baseline variable had an effect on the PFS in univariate and multivariate analysis for the entire cohort. In comparison to antropyloric region, body and multifocal tumour had poorer outcome whereas gastroesophageal junction (GEJ) had good outcome. For OS, response to treatment had a good prognosis and higher platelet count $>400000 / \mathrm{cu} \mathrm{mm}$ conferred a poor prognosis (Table 4 ).

\section{Discussion}

Our study has shown that CAPOX is non-inferior to EOX in terms of ORR, PFS and OS for first line treatment of advanced AGC. A trend favored PFS in EOX arm. However, we observed that there is significantly better tolerability of EOX regimen than CAPOX. Nonhematological toxicity (diarrhea, vomiting) was more in the CAPOX group, and hematological toxicity (neutropenia) was more in the EOX group.

Gastric cancer is a disease of advanced age with a median age of presentation of 65 year in western countries [9]. In our study, the median age of presentation was 55 years that is about one decade earlier. Male outnumbered female with a male to female ratio of 2.23 which is comparable to studies from other Indian states $[10,11]$. Antropyloric region (63\%) was the most common site of disease in our study that is in contrast to the recent increase in the incidence of gastric cancer in gastro-esophageal junction in the western population [12]. In India antropyloric region is still the common site [11]. The mean symptom duration was 3.8 months. About $82 \%$ of the patients had metastatic disease at presentation, which gives an indirect idea of delayed presentation or aggressive course of the disease in our cohort. A distinctive finding observed in our patient cohort was increased baseline platelet count (> 400000/cu mm) in 36\% patients. In multivariate analysis for overall survival high platelet count had a poor outcome. $\mathrm{Li}$, et al. stated that about $7.5 \%$ of patients with AGC 
Table 4: Cox Proportional Hazards estimate for progression-free survival and overall survival.

\begin{tabular}{|c|c|c|c|c|c|c|c|c|c|}
\hline & & \multicolumn{4}{|c|}{ PFS } & \multicolumn{4}{|c|}{ os } \\
\hline \multirow{2}{*}{\multicolumn{2}{|c|}{ Variables }} & \multicolumn{2}{|l|}{ Univariate } & \multicolumn{2}{|c|}{ Multivariate } & \multicolumn{2}{|c|}{ Univariate } & \multicolumn{2}{|c|}{ Multivariate } \\
\hline & & HR $(95 \% \mathrm{Cl})$ & $p$ & HR (95\% Cl) & p & HR (95\%Cl) & $p$ & HR $(95 \% \mathrm{Cl})$ & $\mathrm{p}$ \\
\hline \multirow{3}{*}{ Age } & $\leq 40(15)$ & 1 & & & & 1 & & & \\
\hline & $41-60(38)$ & $0.81(0.41-1.78)$ & 0.541 & & & $1.08(0.51-2.27)$ & 0.840 & & \\
\hline & $>60(16)$ & $0.71(0.31-1.61)$ & 0.417 & & & $0.59(0.21-1.63)$ & 0.312 & & \\
\hline \multirow{2}{*}{ Sex } & Male (51) & 1 & \multirow{2}{*}{0.784} & & & 1 & \multirow{2}{*}{0.958} & & \\
\hline & Female (18) & $.91(0.49-1.69)$ & & & & $1.01(0.50-2.05)$ & & & \\
\hline \multirow{2}{*}{ Performance status } & $1(57)$ & 1 & \multirow{2}{*}{0.677} & & & 1 & \multirow{2}{*}{0.295} & & \\
\hline & $2(12)$ & $0.85(0.41-1.77)$ & & & & $.027(0.26-1.50)$ & & & \\
\hline \multirow{3}{*}{ Weight } & $\leq 40(24)$ & 1 & & & & 1 & & & \\
\hline & $40-60(37)$ & $0.66(0.37-1.20)$ & 0.178 & & & $0.68(0.34-1.34)$ & 0.270 & & \\
\hline & $\geq 60(08)$ & $0.62(0.23-1.68)$ & 0.355 & & & $1.13(0.41-3.12)$ & 0.810 & & \\
\hline \multirow{2}{*}{ Hemoglobin } & $\leq 10(31)$ & 1 & \multirow{2}{*}{0.610} & & & 1 & \multirow{2}{*}{0.248} & & \\
\hline & $>10(38)$ & $0.86(0.49-1.51)$ & & & & $0.68(0.36-1.30)$ & & & \\
\hline \multirow{2}{*}{ Platelet count } & $\leq 4$ lakh (44) & 1 & \multirow{2}{*}{0.726} & & & 1 & \multirow{2}{*}{$0.055^{*}$} & & \multirow{2}{*}{0.007} \\
\hline & >4lakh (25) & $1.10(0.62-1.96)$ & & & & $1.88(0.98-3.58)$ & & $\begin{array}{c}2.97 \\
(1.29-5.19)\end{array}$ & \\
\hline \multirow{4}{*}{ Site } & Antropyloric (39) & 1 & & & & 1 & & & \\
\hline & GEJ (14) & $0.47(.22-.99)$ & $0.047^{*}$ & $0.39(0.18-0.83)$ & 0.015 & $0.424(.16-1.11)$ & 0.081 & & \\
\hline & Multifocal (9) & $1.35(0.58-3.13)$ & 0.484 & $1.15(0.49-2.68)$ & 0.742 & $1.32(0.49-3.51)$ & 3.517 & & \\
\hline & Body (7) & $3.64(1.44-9.20)$ & $0.006^{*}$ & $3.16(1.21-8.22)$ & 0.018 & $1.59(0.60-4.18)$ & 0.347 & & \\
\hline \multirow{2}{*}{ Histology } & Adenoca (67) & 1 & & & & 1 & & & \\
\hline & Squamous cell ca (2) & $0.29(0.18-4.30)$ & 0.638 & & & $0.95(0.12-5.14)$ & 0.862 & & \\
\hline \multirow{2}{*}{ Ascites } & Negative (37) & 1 & \multirow{2}{*}{0.514} & & & 1 & 0556 & & \\
\hline & positive (19) & $1.12(0.65-2.34)$ & & & & $0.53(0.06-4.31)$ & 0.556 & & \\
\hline Stage & $\begin{array}{l}\text { Locally advanced(12) } \\
\text { Metastatic (57) }\end{array}$ & $\begin{array}{c}1 \\
1.01(0.49-2.08)\end{array}$ & 0.974 & & & $\begin{array}{c}1 \\
1.76(0.695-4.58)\end{array}$ & 0.228 & & \\
\hline Prior surgery & $\begin{array}{l}\text { Not done (29) } \\
\text { Done (40) }\end{array}$ & $\begin{array}{c}1 \\
0.74(0.43-1.28)\end{array}$ & 0.289 & & 0.166 & $\begin{array}{c}1 \\
0.72(0.35-1.48)\end{array}$ & 0.379 & & \\
\hline Response category & $\begin{array}{l}\text { CR/PR/SD(43) } \\
\text { PD/UR(25) }\end{array}$ & $\begin{array}{c}1 \\
4.31(2.41-7.73)\end{array}$ & $0.000^{*}$ & $4.69(2.56-8.62)$ & 0.000 & $\begin{array}{c}1 \\
2.43(1.29-4.58)\end{array}$ & $0.006^{*}$ & $\begin{array}{c}2.79 \\
(1.43-5.46)\end{array}$ & 0.003 \\
\hline Dose modification & $\begin{array}{l}\text { Yes(45) } \\
\text { No (24) }\end{array}$ & $\begin{array}{c}1 \\
1.02(0.58-1.81)\end{array}$ & 0.929 & & & $\begin{array}{c}1 \\
0.56(0.29-1.06)\end{array}$ & $0.075^{*}$ & & \\
\hline
\end{tabular}

"Variables with $\mathrm{p}$-value of $<0.25$ were entered into a multivariate analysis.

presented with increased platelet count and this was associated with poor prognosis [13].

The median numbers of chemotherapy cycles administered were 6.5 in CAPOX and 8 in EOX arm respectively. In a phase two trial by Quek, et al. median number of CAPOX cycles administered was five whereas a median of 6 cycles were administered in the EOX arm in the REAL 2 study [5,14]. 42\% patient completed CAPOX and 58\% EOX regimen. The baseline patient profile, responses and toxicities of CAPOX and EOX are comparable to other studies [5,6,14-18]. Both the chemotherapy regimens were well tolerated. Anemia was significantly more in EOX arm whereas non-hematological toxicity such as diarrhea and vomiting were more in CAPOX group. There was a trend of more chemotherapy discontinuation due to grade $3 / 4$ toxicity in the CAPOX arm due to troublesome non-hematological toxicity. The hematological toxicity was well managed without G-CSF support. In the epirubicin, cisplatin, fluorouracil (ECF) vs. cisplatin and fluorouracil (CF) trial, the incidence of neutropenia and mucositis were more in the ECF arm but nausea, vomiting and diarrhea were not significantly different between the groups [19]. The increased incidence of diarrhea and vomiting in our population occurred probably due to intolerance to capecitabine at the study dose as almost $70 \%$ of the patients required dose modification in the CAPOX arm. We consider from our data that the increase in non-hematological toxicities in the CAPOX group is due to the dose of capecitabine in the above regimen. Midgley, et al. mentioned that there need not be a universally applicable starting dose of capecitabine because of interpatient differences in physiology, pharmacogenomics, inter regional geographical and dietary pattern [20]. 
The ORR, PFS, and OS were not significantly different between two groups, though there was a trend favouring PFS in the EOX arm. There are two studies comparing anthracycline-based triplet chemotherapy with platinum and fluorouracil-based doublet such as ECF vs. CF and epirubicin, cisplatin and capecitabine (ECX) vs. cisplatin and capecitabine (CX). In these two studies, there was no significant difference in PFS and OS between the study arms $[19,21]$. Response to treatment was a good prognostic factor for both PFS and OS. On multivariate analysis for PFS, site of disease was the only baseline variable that had an effect on the PFS besides response. In comparison to antropyloric region, body had poorer outcome [HR 3.64 (1.44-9.20), $\mathrm{p}=0.006$ ] whereas GEJ had good outcome [HR $0.474(0.22-.99) \mathrm{p}=0.047]$. On multivariate analysis for OS, higher platelet count $>400000 / \mathrm{cu} \mathrm{mm}$ conferred a poor prognosis. Poorer outcome with higher platelet count $(>400000 / \mathrm{cu} \mathrm{mm})$ was also described by $\mathrm{Li}$, et al. [13]. In a multivariate prognostic factor analysis by Chau, et al. in locally advanced/metastatic gastric cancer patients, ECOG performance status $\geq 2$, high alkaline phosphatase level $(>100$ $\mathrm{U} / \mathrm{L}$ ) and site of metastasis (peritoneum, liver) had poor outcome [22].

\section{Conclusion}

In conclusion, EOX is a better-tolerated regimen than CAPOX with no advantage in RR or OS. PFS trend favoring EOX has to be confirmed with larger sample size and longer follow-up. Whether a modified CAPOX designed to improve tolerance can eliminate the need for epirubicin without loss of efficacy requires evaluation in further study.

\section{Acknowledgement}

We thank Jawaharlal Institute of Postgraduate Medical Education and Research (JIPMER) for providing fund, logistics and other support for carrying out the study. We also thank all the research staff of the participating departments.

\section{Authorship}

Study concept and design: Pani CK, Dubashi B, Verma SK, Sistla SC. Provision of patient and study material: Dubashi B, Sistla SC, Verma SK, Cyriac SL, Kayal S. Data collection and analysis: Pani CK, Kayal S, Dubashi B, Dhanraj KM, Cyriac SL. Manuscript writing: Pani CK, Kayal S, Dubashi B, Cyriac SL. Final approval of manuscript: all authors.

\section{References}

1. Ferlay J, Soerjomataram I, Dikshit R, Eser S, Mathers C, Rebelo M, et al Cancer incidence and mortality worldwide: sources, methods and major patterns in GLOBOCAN 2012. Int J Cancer. 2015; 136: E359-386.

2. Cancer Statistics Review, 1975-2012-SEER Statistics.

3. Wagner AD, Unverzagt S, Grothe W, Kleber G, Grothey A, Haerting J, et al Chemotherapy for advanced gastric cancer. Cochrane Database Syst Rev. 2010; CD004064.

4. Roth AD, Fazio N, Stupp R, Falk S, Bernhard J, Saletti P, et al. Docetaxel, cisplatin, and fluorouracil; docetaxel and cisplatin; and epirubicin, cisplatin, and fluorouracil as systemic treatment for advanced gastric carcinoma: a randomized phase II trial of the Swiss Group for Clinical Cancer Research. J Clin Oncol. 2007; 25: 3217-3223.
5. Cunningham D, Starling N, Rao S, Iveson T, Nicolson M, Coxon F, et al. Capecitabine and oxaliplatin for advanced esophagogastric cancer. $N$ Engl J Med. 2008; 358: 36-46

6. Park YH, Kim BS, Ryoo BY, Yang SH. A phase II study of capecitabine plus 3-weekly oxaliplatin as first-line therapy for patients with advanced gastric cancer. Br J Cancer. 2006; 94: 959-963.

7. Common Terminology Criteria for Adverse Events (CTCAE) CTCAE_4.03_2010-06-14_QuickReference_5x7.pdf

8. Eisenhauer EA, Therasse P, Bogaerts J, Schwartz LH, Sargent D, Ford R, et al. New response evaluation criteria in solid tumours: revised RECIST guideline (version 1.1). Eur J Cancer. 2009; 45: 228-247.

9. Cunningham D, Okines AF, Ashley S. Capecitabine and oxaliplatin for advanced esophagogastric cancer. N Engl J Med. 2010; 362: 858-859.

10. Sambasivaiah K, Ibrarullah M, Reddy MK, Reddy PV, Wagholikar G, Jaiman $S$, et al. Clinical profile of carcinoma stomach at a tertiary care hospital in south India. Trop Gastroenterol. 2004; 25: 21-26.

11. Barad AK, Mandal SK, Harsha HS, Sharma BM, Singh TS. Gastric cancer-a clinicopathological study in a tertiary care centre of North-eastern India. J Gastrointest Oncol. 2014; 5: 142-147.

12. Alberts SR, Cervantes A, van de Velde CJ. Gastric cancer: epidemiology, pathology and treatment. Ann Oncol. 2003; 14 Suppl 2: ii31-36.

13. Li F-X, Wei L-J, Zhang H, Li S-X, Liu J-T. Significance of thrombocytosis in clinicopathologic characteristics and prognosis of gastric cancer. Asian Pac J Cancer Prev. 2014; 15: 6511-6517.

14. Quek R, Lim WT, Foo KF, Koo WH, Toh HC. Capcitabine and oxaliplatin (XELOX) in the treatment of advanced gastric cancer. J Clin Oncol. 200624 14089-14089.

15. Dong N, Jiang W, Li H, Liu Z, Xu X, Wang M. Triweekly oxaliplatin plus oral capecitabine as first-line chemotherapy in elderly patients with advanced gastric cancer. Am J Clin Oncol. 2009; 32: 559-563.

16. Sirohi B, Barreto SG, Singh A, Batra S, Mittra A, Rastogia S, et al. Epirubicin, oxaliplatin, and capectabine is just as "MAGIC"al as epirubicin, cisplatin, and fluorouracil perioperative chemotherapy for resectable locally advanced gastro-oesophageal cancer. J Cancer Res Ther. 2014; 10: 866-870.

17. Mongan AM, Kalachand R, King S, O'Farrell NJ, Power D, Ravi N, et al. Outcomes in gastric and junctional cancer using neoadjuvant and adjuvant chemotherapy (epirubicin, oxaliplatin, and capecitabine) and radical surgery. Ir J Med Sci. 2015; 184: 417-423.

18. Kuo YC, Liu HT, Lin YL, Yang YC, Yang TS, Liau CT, et al. Modified biweekly oxaliplatin and capecitabine for advanced gastric cancer: a retrospective analysis from a medical center. Biomed J. 2014; 37: 141-146.

19. Kim TW, Choi SJ, Ahn JH, Bang HS, Chang HM, Kang YK, et al. A prospective randomized phase III trial of 5-fluorouracil and cisplatin (FP) versus epirubicin cisplatin, and 5-fu (ECF) in the treatment of patients with previously untreated advanced gastric cancer (AGC). Eur J Cancer. 2001; 37: S314.

20. Midgley R, Kerr DJ. Capecitabine: have we got the dose right? Nat Clin Pract Oncol. 2009; 6: 17-24.

21. Yun J, Lee J, Park SH, Park JO, Park YS, Lim HY, et al. A randomised phase II study of combination chemotherapy with epirubicin, cisplatin and capecitabine (ECX) or cisplatin and capecitabine (CX) in advanced gastric cancer. Eur J Cancer. 2010; 46: 885-891.

22. Chau I, Norman AR, Cunningham D, Waters JS, Oates J, Ross PJ. Multivariate prognostic factor analysis in locally advanced and metastatic esophago-gastric cancer--pooled analysis from three multicenter, randomized, controlled trials using individual patient data. J Clin Oncol. 2004; 22: 2395-2403.
Austin J Cancer Clin Res - Volume 4 Issue 1 - 2017 ISSN : 2381-909X | www.austinpublishing group.com Kayal et al. (C) All rights are reserved
Citation: Pani CK, Dubashi B, Cyriac SL, Dhanraj KM, Verma SK, Sistla SC, et al. First Line Treatment for Advanced Gastroesophageal Cancer: Capecitabine Plus Oxaliplatin (CAPOX) versus Epirubicin, Oxaliplatin Plus Capecitabine (EOX). Austin J Cancer Clin Res. 2017; 4(1): 1073. 